Dietrich Helms (Osnabrück)

\title{
Zum Gedenken an Thomas Phleps (1955-2017)
}

Thomas Phleps starb am 5. Juni 2017 im Alter von 61 Jahren an einem Herzinfarkt. Sein besonderes Interesse als Forschender und Musiker galt der Musik des 20. Jahrhunderts in ihren gesellschaftlichen und besonders politischen Kontexten. Dementsprechend kannte er in seiner wissenschaftlichen Arbeit keine Grenzen zwischen Populärem und Kunst, zwischen U und E. Die Forschung zur Musik Hanns Eislers und Stefan Wolpes hat ihm wichtige Beiträge auch als Herausgeber zu verdanken. Gleichzeitig war er ein Spezialist für den frühen US-amerikanischen Blues und die sogenannte „Black Music“ sowie die Rock Avantgarde der späten 1960er und 1970er Jahre. Mit seinen Arbeiten zur Rolle der Musikpädagogik und der Musikwissenschaft in der Nazi-Zeit sprach er Wahrheiten aus, über die viele noch gern geschwiegen hätten. Wissenschaftliches Arbeiten hatte für ihn immer auch mit Leidenschaft für den Gegenstand und mit Überzeugung zu tun: von der Wahrhaftigkeit sowie der Richtigkeit und Angemessenheit wissenschaftlichen Tuns auch im größeren, gesellschaftlichen Zusammenhang. Wie wenige andere wusste er Sprache zu schleifen: so präzise wie möglich und so assoziativ wie nötig, um mit seinem Denken Nachdenken anzuregen.

Thomas Phleps wurde am 2. September 1955 in Bad Hersfeld geboren. 1981 und 1983 legte er die Staatsprüfungen für das Lehramt an Mittel- und Oberstufen in Musik, Deutsch und Philosophie an den Universitäten Marburg und Kassel ab. Anschließend arbeitete er als Lehrbeauftragter für Musikwissenschaft und Gitarre an der Universität Gesamthochschule Kassel. Dort wurde er 1987 mit einer Dissertation zu Hanns Eislers Deutscher Sinfonie, betreut von Helmut Rösing, promoviert. Er arbeitete u. a. als Bühnenmusiker und Jugendreferent für das Staatstheater Kassel und als Musik- und Deutschlehrer. 1995 wurde er auf eine Hochschuldozentur für Musikpädagogik an die Justus-Liebig-Universität Gießen berufen, wo er sich 2000 mit Forschungen zum Thema „Zwischen Spätklassik und HipHop - Methoden und Modelle. Musikanalytische, musikhistorische und musikdidaktische Studien “ habilitierte und die Lehrbefugnis für die Fächer Musikwissenschaft und Musikpädagogik erhielt. 2001 nahm er einen Ruf auf die musikpädagogische Professur am Studiengang Musik/Musikwissenschaft der Universität Bremen an. 2003 wechselte er als Professor für Musikpädagogik an die Universität Gießen. In Gießen setzte er sich u. a. als Institutsdirektor erfolgreich für die Weiterentwicklung der Lehramtsstudiengänge ein.

Als Herausgeber machte er sich für die Werke Stefan Wolpes stark und edierte seine Lieder, Klaviermusik und Ensemblestücke für das Kabarett. Von 1993 an wirkte er als Mitglied des Editorial Committee der Stefan Wolpe Society. 2010 übernahm er die Aufgabe des Editionsleiters (Noten) der Hanns Eisler Gesamtausgabe (HEGA). Die Ausgabe von Eislers Deutscher Symphonie, an der er zusammen mit Johannes C. Gall arbeitete, konnte er nicht mehr fertigstellen. Seit 1997 gehörte er ununterbrochen dem Vorstand des Arbeitskreises Studium Populärer Musik (seit 2014 Gesellschaft für Popularmusikforschung) an. Als Herausgeber der Publikationen des ASPM/der GfPM veröffentlichte er allein und mit verschiedenen Mitherausgebern u. a. 19 Bände der Beiträge zur Popularmusikforschung und 15 Jahrgänge der von ihm mitbegründeten Online-Zeitschrift SAMPLES. Als Gitarrist und Arrangeur wirkte Phleps im Hanns Eisler Ensemble sowie in verschiedenen Blues Bands mit. 